\title{
Application of thermography for determination the radiator capacity
}

\author{
by M. Malinovec and S. Svaic
}

University of Zagreb, Faculty of Mechanical Engineering and Naval Architecture, Department for Process and Thermal Engineering, Ivana Lucica 5, 10000 Zagreb, Croatia,E-mail: srecko.svaic@fsb.hr,marina.malinovec@fsb.hr

\begin{abstract}
:
The paper presents comparison between analytical and experimental determination of the parameters responsible for radiator rib capacity. Thermography was applied for measuring the temperature distribution on the fin surface from which the local heat transfer coefficients has been calculated as well as the fin characteristic. Those values were compared against the results obtained by theoretical calculations. Analytical solution of the temperature distribution on the rib surface gives the approximate results that can be used in the first step of a rib design. Comparing the calculations and experiments, where thermography is used, more information about rib characteristics can be obtained. For complete analysis the 3D numerical model and thermographic measurements are suggested.
\end{abstract}

\section{Introduction}

Determination of the radiator capacity is proposed by the accepted EN or ISO standards. The measurement must be performed in the specially designed testing room with radiator in steady state conditions.

In the design process of the radiator fin the basic problem that designer is faced with is how to find the rate of heat dissipated by the fin and the variation of the fin temperature from the base to the top for a given fin configuration. The paper presents the method by which the local heat transfer coefficients can be calculated from the thermograms, which represent the temperature distribution on the fin surface. The heat transfer coefficient and temperatures must be known if the heat dissipated by the fin is to be calculated.

The rib profile analysed in the work is given on Figure 1. Experimental part of the work has been done on the testing rig shown on Figure 2. The FLIR IR camera model AGEMA 570 PRO is used for recording of thermograms.

\section{Extended surfaces}

When the heat transfer between the rib and surrounding must be increased it is common practice to use extended surfaces. In most cases the radiator rib is the configuration which consists of primary surface and straight fins attached on it. If one assumes that the radiator rib is divided in segments (see Figure 1) and each segment is in a steady state and inserted into the ambient having the constant temperature, the problem of solving the temperature distribution and heat flux rate becomes one-dimensional conduction problem. If not, it must be solved as 2D or 3D numerical problem.

\subsection{The straight fin of uniform thickness}

Usually when dealing with straight fins it is customary to neglect heat losses from the side edges of the fin and to express the heat flow per unit width. For straight fin of uniform thickness shown on Figure 3 one can write according to [1] for the excess temperature

$$
\vartheta_{b}=\frac{\vartheta_{0}}{c h(m b)}
$$


and for the heat flow rate

where $\quad x=b: \vartheta=\vartheta_{0}=t_{0}-t_{f} ; \quad x=0: \frac{\mathrm{d} \vartheta}{\mathrm{d} x}=0$

$$
q_{b}=\lambda \cdot \delta \cdot m \cdot \vartheta_{0} \cdot \operatorname{th}(m b)
$$

$$
m=\sqrt{\frac{2 \cdot \alpha}{\lambda \cdot \delta}}, \quad \vartheta=t-t_{f}
$$

and

$\alpha$ - heat transfer coefficient, $\lambda$ - heat conductivity, $\delta$ - fin thickness

The heat loss at the end of the fin is neglected.

\subsection{Rib profile with closed fins}

For the radiator rib profile shown on Figure 4 one can write according to [1] for the excess temperature

where

$$
\vartheta_{b}=F_{1} \cdot \vartheta_{0}
$$

$$
F_{1}=\frac{1}{\operatorname{ch}(m b)+\sqrt{2} \cdot \operatorname{th}(m a) \cdot \operatorname{sh}(m b)}
$$

and

$$
\vartheta_{a}=\frac{F_{1} \cdot \vartheta_{0}}{c h(m a)}
$$

also for the heat flow rate

$$
\begin{gathered}
q_{b}=\frac{2 \cdot \alpha \cdot F_{1} \cdot \vartheta_{0}}{m} \cdot[\operatorname{sh}(m b)+\sqrt{2} \cdot \operatorname{th}(m a) \cdot(\operatorname{ch}(m b)-1)] \\
q_{a}=\frac{\alpha \cdot F_{1} \cdot \vartheta_{0}}{m} \cdot \operatorname{th}(m a)
\end{gathered}
$$

\section{Measurement}

The radiator rib with the cross section given on Figure 1 was mounted on the experimental rig. The rib was in steady state. The water flow rate was constant and the inlet and outlet water temperatures were $90 / 70^{\circ} \mathrm{C}$. On the base of measurement done before the following assumptions were adopted:

- The air temperature on the outer side is ambient temperature $t_{a f}$

- The air temperature between the fins is changed along the rib as:

$$
t_{f}=53.2 \cdot L^{0.15} ; 0<L<0.69
$$

- The temperature of the fin base is changed with the rib height as:

$$
t_{r}=19.9 \cdot H+65.6 ; 0<H<1
$$

- The mean air temperature for outer fins is an arithmetic mean value of $t_{a f}$ and $t_{f}$

$$
t_{a}=\frac{t_{a f}+t_{f}}{2}
$$

- The mean air temperature for inner fins is $t_{f}$.

The rib is made of aluminium alloy with the heat conduction coefficient $\lambda=220 \mathrm{~W} / \mathrm{mK}$. All fins have thickness of $\delta=0.0012 \mathrm{~m}$.

\subsection{Thermograms}

The four thermograms were taken for each segment of the rib as shown on Figure 5 and the temperatures recorded for the referent points. The temperatures were used for further 
determination of the local parameter $m$ for outer fins and factor $F_{1}$ for inner fins.

\subsection{Analysis}

Temperature distribution on outer surfaces clearly shows the contact region of inner and outer fins (points 1, 2 and 4 on Figure 5). The thermograms were analysed for each rib segment and temperatures in relevant points were used for calculation of the parameter $m$ and $F_{1}$. The results are presented in Table $I$ and $I I$ for cross section $A, B$ and $C$. The parameter $m$ has been calculated from (4) using inverse hyperbolic function (11).

$$
m a=\ln \left(x+\sqrt{x^{2}-1}\right), \quad \text { where } x=\operatorname{ch}(m a)
$$

Table I: Factor $m$ and local heat transfer coefficient $\alpha$ obtained from measured values

\begin{tabular}{|c|c|c|c|c|c|}
\hline & & $1-2$ & $2-3$ & $3-4$ & $4-5$ \\
\hline \multirow{2}{*}{$\mathrm{A}$} & $m$ & 9.9 & 4.7 & 7.6 & 8.8 \\
\cline { 2 - 6 } & $\alpha$ & 8.7 & 6 & 7.6 & 8.2 \\
\hline \multirow{2}{*}{$\mathrm{B}$} & $m$ & 9.3 & 7.8 & 8.4 & 4.9 \\
\cline { 2 - 6 } & $\alpha$ & 8.4 & 7.7 & 8 & 6.1 \\
\hline \multirow{2}{*}{$\mathrm{C}$} & $m$ & 9.7 & 5.7 & 9.3 & 9.7 \\
\cline { 2 - 6 } & $\alpha$ & 8.6 & 6.6 & 8.4 & 8.6 \\
\hline
\end{tabular}

It must be noticed that the factors $m$ and $F_{1}$ are very sensitive to temperatures. Due to this the thermograms must be taken with the maximal possible IR camera sensitivity.

Table II: Factor $F_{1}$ obtained from measured values

\begin{tabular}{|c|c|c|c|}
\hline$F_{1}$ & 1 & 2 & 4 \\
\hline $\mathrm{A}$ & 0.85 & 0.89 & 0.87 \\
\hline $\mathrm{B}$ & 0.87 & 0.9 & 0.87 \\
\hline $\mathrm{C}$ & 0.87 & 0.9 & 0.87 \\
\hline
\end{tabular}

\section{Calculations}

For the first step in a design of a radiator rib the heat transfer coefficient for each segment can be calculated from equation (12) which gives the correlation for Nusselt number on vertical plane surfaces exposed to free convection, laminar flow.

$$
\mathrm{Nu}=\frac{\alpha_{c} \cdot h}{\lambda}=0.517 \cdot(\mathrm{Gr} \cdot \mathrm{Pr})^{1 / 4}, \text { for } 10^{4}<\mathrm{Gr} \cdot \mathrm{Pr}<10^{8} \text { and } \operatorname{Pr}=0.73
$$

With temperatures of the fin and the surrounding equal to those in measurement the value of the local convective heat transfer coefficient obtained from relation (12) is $\alpha_{c}=6.1 \mathrm{~W} / \mathrm{m}^{2} \mathrm{~K}$. Assuming the radiative heat transfer coefficient of $\alpha_{r}=2.4 \mathrm{~W} / \mathrm{m}^{2} \mathrm{~K}$ according to (13)

where

$$
\alpha_{r}=\varepsilon \cdot \sigma \cdot F_{1-2} \cdot \frac{\left(\frac{T_{1}}{100}\right)^{4}-\left(\frac{T_{2}}{100}\right)^{4}}{T_{1}-T_{2}}
$$

$$
\varepsilon=0.96 \text {-emissivity, } \sigma=5.67 \mathrm{~W} / \mathrm{m}^{2}(100 \mathrm{~K})^{4}, F_{1-2}=0.35 \text { shape factor }
$$

the total local heat transfer coefficient for the fin segment is $\alpha_{t}=8.5 \mathrm{~W} / \mathrm{m}^{2} \mathrm{~K}$ defined by

$$
\alpha_{t}=\alpha_{c}+\alpha_{r}
$$

With total heat transfer coefficient calculated from (14) and relations (1) and (4) the temperatures in relevant points were determined. For the cross section $A, B$ and $C$ the results are presented in Table III together with measured ones.

Table III: Measured* and calculated temperatures in relevant point on the fin 
http://dx.doi.org/10.21611/qirt.2000.017

\begin{tabular}{|c|c|c|c|c|c|}
\hline $\mathrm{t},{ }^{\circ} \mathrm{C}$ & 1 & 2 & 3 & 4 & 5 \\
\hline \multirow{2}{*}{$\mathrm{A}$} & $77.8^{*}$ & $79.2^{\star}$ & $78.3^{*}$ & $78.6^{*}$ & $77.9^{\star}$ \\
\cline { 2 - 6 } & 77.3 & 78.7 & 78 & 80.6 & 79.8 \\
\hline \multirow{2}{*}{$\mathrm{B}$} & $76.2^{\star}$ & $77.5^{\star}$ & $76.2^{\star}$ & $76.5^{\star}$ & $76^{\star}$ \\
\cline { 2 - 6 } & 75.3 & 76.7 & 76.1 & 78.5 & 77.7 \\
\hline \multirow{2}{*}{$\mathrm{C}$} & $73.8^{*}$ & $75.1^{*}$ & $73.7^{*}$ & $74^{*}$ & $73.5^{\star}$ \\
\cline { 2 - 6 } & 73 & 74.3 & 73.7 & 76.1 & 75.3 \\
\hline
\end{tabular}

Factor $F_{1}$ calculated according to (5) is given in Table IV

Table IV: Calculated values of factor $\mathrm{F}_{1}$

\begin{tabular}{|c|c|c|c|}
\hline \multirow{2}{*}{$F_{1}$} & 1 & 2 & 4 \\
\cline { 2 - 4 } & 0.83 & 0.88 & 0.93 \\
\hline
\end{tabular}

The differences between measured and calculated temperatures are evident for the point 4 and 5. The reason is probably the asymmetrical configuration of fins on the fin base. Calculated and measured values for the factor $F_{1}$ responsible for temperatures in the point 4 differ too.

\section{Conclusion}

Analytical solution of the temperature distribution on the rib surface gives the approximate results that can be used in the first step of the radiator rib design. It is also valid for some special rib configuration when the symmetry is assured. To determine the final geometry of the rib a thermography could provide a lot of help to designer to find optimal dimensions of the fins and good temperature distribution over the whole profile. From thermographic measurement the main fin parameters could be calculated in terms of the factors $m$ and $F_{1}$ which give information about the heat dissipated to surrounding. It must be noticed that temperature reading from thermograms must be very accurate because of their influence on the factors $m$ and $F_{1}$. Although the knowledge of air temperature distribution between fins and on the fin base must be known if the complete analysis is to be carried out. To attain more reliable data it is recommended to apply the 3D numerical model of a radiator rib with boundary conditions obtained from thermographic measurement

\section{References}

[1] КЕРН, Д. and KРАYС, А., " РАЗВИТЫЕ ПОВЕРХНОСТИ ТЕПЛООБМЕНА ", МOСКВА, «ЭНЕРГИЯ» 1977

[2] MODIC, J. , " Določanje optimalne moči rebrastih ogreval ", Interklima, Zagreb, 1977, p 205-232

[3] CHAPMAN, A.J. , "Heat transfer", Macmilan Publishing Company, New York, 1984

[4] KAKAC, S. and YENER, Y. , "Convective heat transfer ", CRC Press, Florida, 1995 

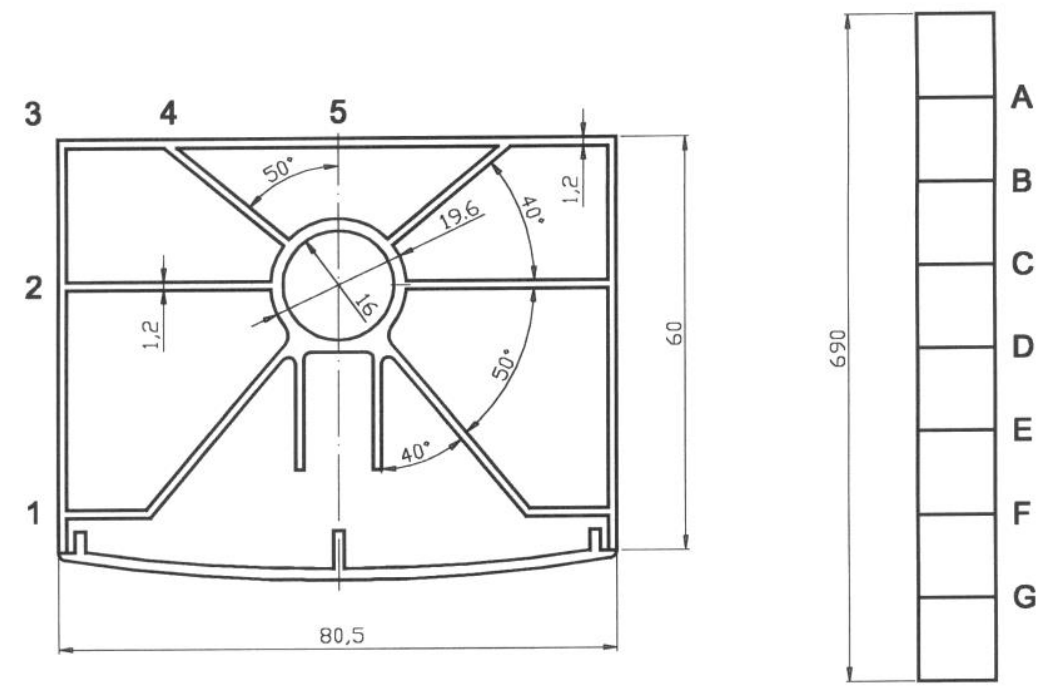

Figure 1 : Rib profile

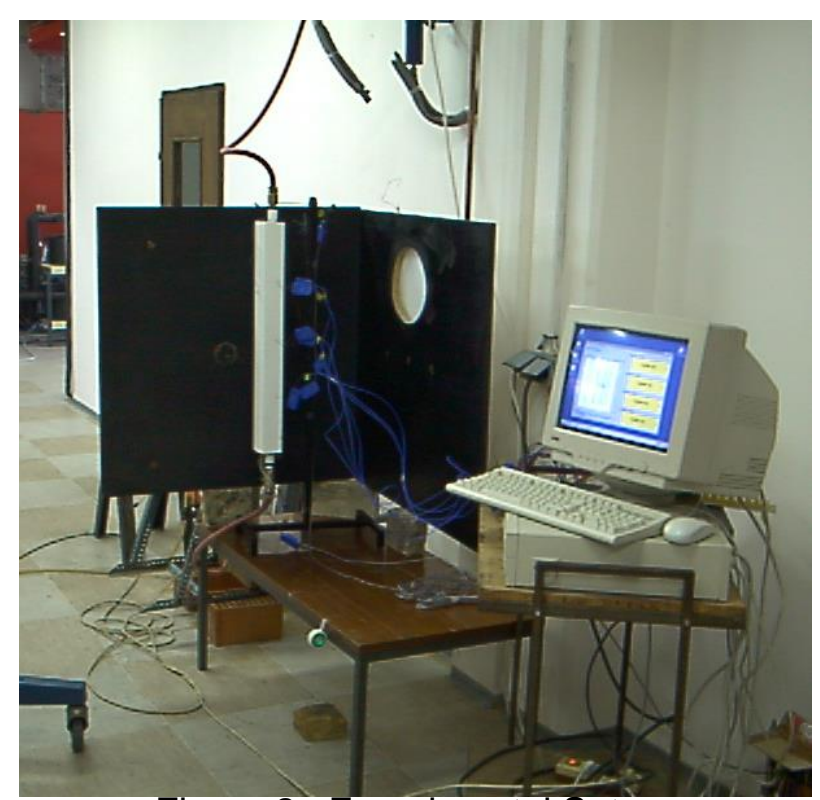

Figure 2 : Experimental Set-up

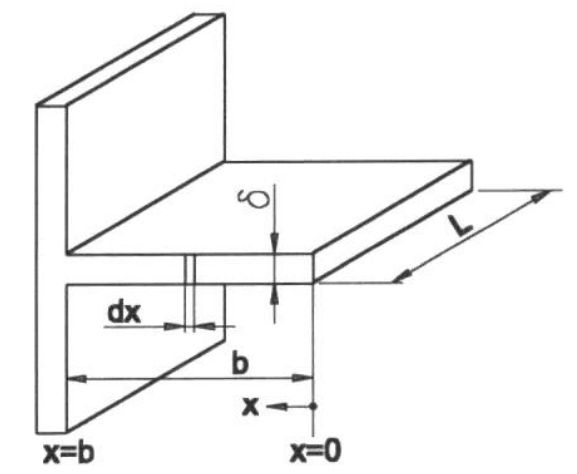

Figure 3 : Straight fin profile of a uniform thickness 
http://dx.doi.org/10.21611/qirt.2000.017

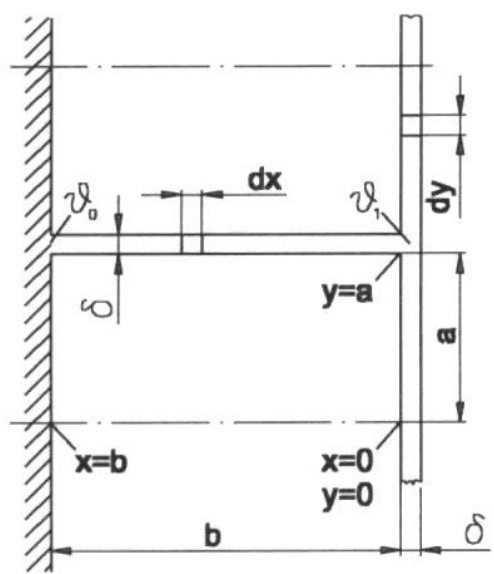

Figure 4 : Closed rib profile
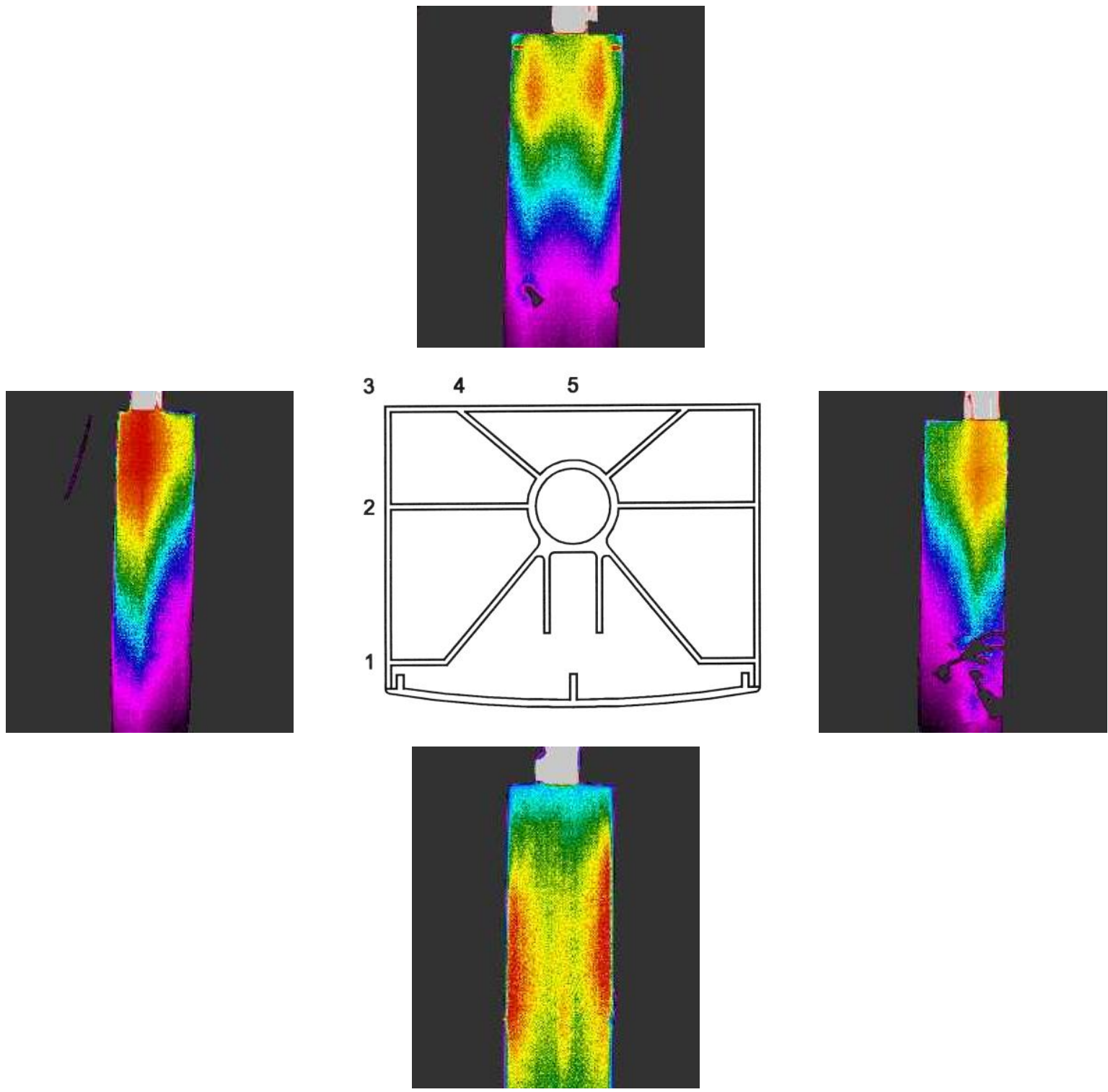

Figure 5 : Thermograms of the radiator profile segment 